\title{
Laser Ablation for Small Hepatocellular Carcinoma
}

\author{
Claudio Maurizio Pacella, ${ }^{1}$ Giampiero Francica, ${ }^{2}$ and Giovanni Giuseppe Di Costanzo ${ }^{3}$ \\ ${ }^{1}$ Department of Radiology and Diagnostic Imaging, Regina Apostolorum Hospital, Albano Laziale, 00041 Rome, Italy \\ ${ }^{2}$ Ultrasound Unit Gastroenterology Department, S. Maria della Pietà Hospital, Casoria, 80026 Naples, Italy \\ ${ }^{3}$ Hepatology Unit, A. Cardarelli Hospital, 80131 Naples, Italy
}

Correspondence should be addressed to Giampiero Francica, giampierofrancica@gmail.com

Received 13 July 2011; Accepted 20 October 2011

Academic Editor: David Maintz

Copyright (C) 2011 Claudio Maurizio Pacella et al. This is an open access article distributed under the Creative Commons Attribution License, which permits unrestricted use, distribution, and reproduction in any medium, provided the original work is properly cited.

\begin{abstract}
Hepatocellular carcinoma (HCC) is one of the most common malignancies worldwide and is increasingly detected at small size $(<5 \mathrm{~cm})$ owing to surveillance programmes in high-risk patients. For these cases, curative therapies such as resection, liver transplantation, or percutaneous ablation have been proposed. When surgical options are precluded, image-guided tumor ablation is recommended as the most appropriate therapeutic choice in terms of tumor local control, safety, and improvement in survival. Laser ablation (LA) represents one of currently available loco-ablative techniques: light is delivered via flexible quartz fibers of diameter from 300 to $600 \mu \mathrm{m}$ inserted into tumor lesion through either fine needles ( $21 \mathrm{~g}$ Chiba needles) or large-bore catheters. The thermal destruction of tissue is achieved through conversion of absorbed light (usually infrared) into heat. A range of different imaging modalities have been used to guide percutaneous laser ablation, but ultrasound and magnetic resonance imaging are most widely employed, according to local experience and resource availability. Available clinical data suggest that LA is highly effective in terms of tumoricidal capability with an excellent safety profile; the best results in terms of long-term survival are obtained in early HCC so that LA can be proposed not only in unresectable cases but, not differently from radiofrequency ablation, also as the firstline treatment.
\end{abstract}

\section{Introduction}

Hepatocellular carcinoma (HCC) is the sixth most common malignancy worldwide and the third leading cause of cancerrelated death [1]. Its incidence is continually rising mostly as a result of the spread of hepatitis $\mathrm{C}$ virus infection [24]. Patients with chronic hepatitis $B$ or $C$ virus infection are at high risk of developing HCC. The annual incidence of HCC in hepatitis B virus infection carriers is approximately $0.5-1 \%$ and reaches $2.5 \%$ in the presence of liver cirrhosis $[5,6]$. The incidence of HCC in chronic hepatitis C-related liver cirrhosis is up to $2-8 \%$ [6-8]. With surveillance of the high-risk population by ultrasonography and $\alpha$-fetoprotein (AFP), HCC is increasingly detected at small size, that is, $5 \mathrm{~cm}$ or smaller in diameter [9-11]. However, a careful multidisciplinary assessment of tumor characteristics, liver function, and physical status is required for proper therapeutic management even in patients with early-stage tumors [12]. Approximately, $30 \%$ to $40 \%$ of all HCC patients have early tumors which can be treated with curative therapies such as resection, liver transplantation, or percutaneous ablation [12]. While surgical resection provides favourable long-term survival $[13,14]$, only a minority of patients are suitable for resection owing to multiple tumor nodules, concomitant decompensated liver cirrhosis, lesion location, and/or severe portal hypertension. Similarly, surgical resection carries a significant associated morbidity and mortality as well as a disease recurrence rate of up to $75 \%[15,16]$. Liver transplantation is more indicated in small HCC associated with severe cirrhosis and offers a satisfactory long-term outcome [16-18], but the shortage of donor organs significantly limits its application. When surgical options are precluded, imageguided tumor ablation is recommended as the most appropriate therapeutic choice and is considered a potentially radical treatment in properly selected candidates [12]. This technique is also cost effective in comparison to other treatments and is able to maximize the preservation of surrounding liver parenchyma whilst reducing in-patient hospitalization rates $[12,19,20]$. However, whether or not percutaneous ablation can compete with surgery as the first-line treatment 
remains highly controversial and subject of debate. Laser ablation (LA) represents one of a range of currently available loco-ablative techniques with the majority of reported data coming from Italy, Germany, and the UK [21].

\section{General Principles and Techniques}

2.1. Image-Guided Tumor Ablation. The term "image-guided tumor ablation" is defined as the direct application of chemical or thermal therapies to a specific focal tumor(s) in an attempt to achieve eradication or substantial tumor destruction [22]. Over the past 25 years, several methods for chemical or thermal tumor destruction have been developed and clinically tested [23], and image guidance is critical to the success of these therapies $[21,24]$. Although tumor ablation procedures can be performed at laparoscopy or surgery, most procedures treating focal lesions are performed with percutaneous approach, explaining why these procedures are often referred to as "percutaneous therapies."

Thermal energy sources such as laser, radiofrequency (RF), or microwave (MW) make the destruction of tumors possible without surgical removal. The potential advantages of in situ tumor ablation include decreased costs, reduced morbidity, the possibility of performing procedures on outpatients, and the possibility of treating patients who are poor candidates for surgery due to age, comorbidity, or extent of disease. The thermal ablation therapies involved in clinical practice can be classified as either hyperthermic treatments, including RF ablation (RFA), laser ablation (LA), MW ablation (MWA), and high-intensity focused ultrasound (HIFU) or cryoablation (CA). The thermal damage caused by heating depends on both the tissue temperature reached and on the duration of heating. On the other hand, freezing tissue at temperatures between $-20^{\circ} \mathrm{C}$ and $-60^{\circ} \mathrm{C}$, followed by rapid thawing, results in cell membrane disruption and induces cell death. In order to adequately destroy tumor tissue, the entire target volume must be subjected to cytotoxic temperatures [25].

2.2. Laser Ablation. The term "laser ablation" refers to the thermal destruction of tissue by conversion of absorbed light (usually infrared) into heat and includes various technical variations on this theme including "interstitial photocoagulation", "laser coagulation therapy", "laser interstitial tumor therapy", and "laser-induced thermal therapy" [26-34]. Neodymiun:yttrium aluminum garnet (Nd:YAG) lasers with a wavelength of $1064 \mathrm{~nm}$ are usually used for percutaneous LA because penetration of light is optimal in the near infrared spectrum [35]. In recent years, diode lasers with suitable wavelengths have also been used [36]. Laser light penetrates directly for a distance of between $12-15 \mathrm{~mm}$ as a result of backward and forward scattering and reflection and absorption. Scattering results in a relatively uniform distribution of absorbed energy, and heat is produced by conversion of absorbed light. Further away from the point of application, the tissue is heated by conduction creating large coagulative zones $[27,29,30]$. Temperature above $60^{\circ} \mathrm{C}$ results in a rapid coagulation zone and instant cell death. Irreversible cell death, without preceding coagulation, occurs also at lower hyperthermic temperatures $\left(>42^{\circ} \mathrm{C}\right)$ but requires durations of treatment that vary negatively with temperature $[29,30$, $37,38]$. Thus, it has been shown that LA at $46^{\circ} \mathrm{C}$ requires treatment for 30 minutes to ensure radicality [29, 39]. Temperatures above $100^{\circ} \mathrm{C}$ will cause vaporization from evaporation of tissue water, and above $300^{\circ} \mathrm{C}$, tissue carbonization occurs. Overheating is thus best avoided as carbonization decreases optical penetration and heat conduction and limits the size of lesions produced [33].

A high optical penetration depth reduces the temperature gradient between the laser fiber and tissue and lessens the risk of overheating which prevents carbonization and vaporization of tissue [33]. The optical penetration depth is greater in metastatic tissue than in normal liver, being 4.2 and $3.0 \mathrm{~mm}$, respectively, at the 1064 wavelength. Coagulation necrosis reduces optical penetration by about $20 \%$ in both normal and tumor tissue $[33,40]$.

Using a bare tip, almost spherical lesions with a maximum diameter of $12-16 \mathrm{~mm}$ can be produced [21]. Lesion size can be increased by using beam splitters for simultaneous use of multiple fibers in an array around the tumor $[32,41]$. This avoids the problem of repositioning single fibers and the difficulties associated with treatment-induced imaging artifacts. In vitro studies have shown that simultaneous treatment with four fibers at $2.0 \mathrm{~cm}$ separation produces lesions that are 11 times bigger than those produced with a single fiber, creating a lesion cylinder $4.0 \mathrm{~cm}$ in diameter and $3 \mathrm{~cm}$ in height [42]. Simultaneous multifiber treatment produces lesions averaging $3.6 \times 3.1 \times 2.8 \mathrm{~cm}$ in normal canine liver [41]. Bare fibers are now being replaced more and more often by specially designed fibers equipped with diffuser endings that emit light up to a distance of $10-30 \mathrm{~mm}$ and with liquid cooling that increases lesion size by allowing higher power while avoiding charring $[43,44]$. By simultaneously inserting four fibers and using fiber cooling, tumors with a diameter of $5.0 \mathrm{~cm}$ can be safely eradicated in a single treatment session, as reported in the largest series of local ablation in a single institution [45]. Recently, using a $980 \mathrm{~nm}$ diode laser ablation system in an in vivo tumor model with an internally cooled applicator, large ellipsoid thermal ablation with sharp boundaries was obtained in less than 3 minutes [36].

Local tissue properties, in particular perfusion, have a significant impact on the size of ablative zone. Highly perfused tissue and large vessels act as a heat sink, as laser light is absorbed by erythrocytic heme and transported from the local area [46]. This phenomenon makes native liver parenchyma relatively more resistant to LA than tumor tissue and is the basis for the use of hepatic inflow occlusion techniques in conjunction with laser therapy such as local arterial embolization [47-51].

One advantage of using laser technology is that there are sophisticated systems for controlling ablative lesion characteristics and size using feedback systems, and dose-planning systems are available with laser technology [39, 42, 52-54]. An important practical advantage over other thermal sources is that the thin and flexible laser fibers make it possible to reach tumors more easily and safely [55].

Light is delivered via flexible quartz fibers with a diameter from 300 to $600 \mu \mathrm{m}$. Conventional bare tip fibers provide 
a near spherical lesion about $15 \mathrm{~mm}$ diameter at their ends but have been largely replaced by interstitial fibers, which have flat or cylindrical diffusing tips and are $10-40 \mathrm{~mm}$ long, providing a much large ablative area of up to $50 \mathrm{~mm}[56,57]$. The use of beam splitting devices allows for the use of up to four fibers at once with corresponding increase in ablative volume: multiple fibers must be placed, however, and the devices only work effectively at lower powers [55]. By increasing laser power, light transmission improves and the ablative zones increase in size. However, increasing laser power also causes local temperature to rise, leading to the risk of overheating and carbonization of adjacent tissue. The use of water-cooled laser application sheaths allows a higher laser power output (up to $50 \mathrm{~W}$ compared with $5 \mathrm{~W}$ ) while preventing carbonization [58]. Thus, the use of multiple water-cooled higher-power fibers allows ablative zones of up to $80 \mathrm{~mm}$ diameter [44]. Water-cooled sheaths do require wider-bore cannulas but are commonly placed via a coaxial dilatation system from an $18 \mathrm{G}$ puncture. Recently, a novel ablation laser system consisting of a $15 \mathrm{~W}, 980 \mathrm{~nm}$ diode laser, flexible diffusing-tipped fiber optic, and 17-gauge internally cooled catheter was introduced in clinical practice; it achieves a large well-circumscribed ellipsoid ablation zone up to $42 \mathrm{~mm}$ in greatest diameter (with the lasers operating at $15 \mathrm{~W}$ for 120 seconds and two applicators) with sharp boundaries between thermally ablated tumor in the center surrounded by viable tumor tissue [36].

2.3. Real-Time Monitoring and Treatment Planning. Of the range of imaging modalities available to guide percutaneous laser ablation, the choice is based largely on local experience and resource availability. Local tumor destruction with heat is based on the assumption that the whole tumor can be selectively destroyed by raising tumor temperature to a critical level for a definite period of time. This can be ensured by a method that gives good thermal resolution of the relevant tissue or, preferably, accurate real-time monitoring of irreversible tissue damage. Non-invasive techniques are ideal for clinical thermometry, but none yet fulfills the requirements of routine clinical use.

Ultrasound- (US-) guided needle placement has the advantage that it is quick, portable, and widely available; it is familiar also to those used to performing US-guided biopsies. The main disadvantage is that it offers little reliable indication of the temperature or actual extent of the ablative zone being created. In addition, US is not well suited because of treatment-induced artifacts $[48,59,60]$. CT is not useful for real-time monitoring because thermal tissue changes are not visible within 24 hours [61].

In contrast, magnetic-resonance- (MR-) guided LA, often in conjunction with liver specific contrast agent, offers real-time thermal mapping that allows the operator to visualize the size, location, and temperature of the ablation zone $[58,62]$. This technique tends to be used in combination with the higher-power water-cooled laser systems as the increased energy can be delivered in a safe and controlled manner $[63,64]$. However, MR-guided LA is limited by machine availability and the procedural complexity with an overall procedure time between 60 and 120 minutes [45, 65]. This may explain why laser ablation is not widely used compared with RF ablation. Newly developed MR-compatible applicators allow performance of the whole procedure in the MR suite, which may reduce procedure time and improve technical effectiveness. This is under investigation in clinical trials [66].

US-guided laser systems, instead, tend to use multiple lower-power fiber with a lower total energy delivery resulting in truly quick procedure time $[55,67]$. It is possible to achieve a mean ablation zone diameter of $3.0 \mathrm{~cm}$ with this technique with a single illumination of 6 minutes [55].

Thermal imaging can be performed on most MR systems, with thermal changes being easier to demonstrate as magnet field strength increases. There are several methods of measuring tissue temperature changes with MR. The simplest, and most widely used technique, is measuring modifications in $\mathrm{T} 1$ value of tissues which decreases in linear relationships with increasing tissue temperature up to approximately $55^{\circ} \mathrm{C}$ [68]. Techniques that measure changes in the tissue diffusion are more accurate, up to $\pm 1^{\circ} \mathrm{C}$, but require long acquisition times and, therefore, suffer from patient motion artifacts [69]. Another technique measures changes in the proton resonance frequency shift (phase shift). Again, this measures temperature changes very accurately but is not suitable for use in fatty tissue and is less suited to open MR units as it requires a homogeneous magnetic field [70]. All of these techniques are best used in combination with subtraction techniques, that is, pretreatment image subtraction from heating image, which allows very accurate assessment of lesion size, but is sensitive to motion and misregistration artifacts [71].

In addition to thermometry, the use of "open" magnets with the inherent lower field and gradient strengths allows real-time imaging of needle placement in a multiplanar manner, at variance with CT and is not limited by the presence of bone or gas, unlike US. The drawbacks of open magnets are the lower image quality and the increased scan time.

In contrast, conventional closed magnets require fiber placement using CT or US with subsequent transfer into MR scanner for thermal mapping. This has the disadvantage of requiring patient transfer mid procedure although it does provide faster imaging and thermal mapping than an open system [43,67]. The use of MR guidance and thermometry is currently only feasible with LA systems, as it uses a completely metal free system and does not produce any radiofrequency interference $[68,69]$. Most RF systems are currently not suitable for MR usage, both because of steel within the electrodes and the degradation of image quality by extraneous RF noise produced by the RF generators. Although MRcompatible systems have been developed in practice, the RF noise remains problematic [72].

Considering the difficulties in real-time imaging, it is important that methods based on the production of heat ensure reproducible and cytotoxic temperatures in the periphery of tumor tissue. One way to ensure this is to use feedback control of the treatment effect, for example, to let measured temperatures control the energy output in order to achieve a constant temperature level and reproducible lesion size $[39,52]$. Another way to control lesion size is to use a doseplanning system. This has been developed for LA and enables 
lesion size to be calculated for different tissues, output powers, and treatment duration $[42,73]$.

2.4. Patients. Selection criteria vary from unit to unit depending on the technique used and the facilities available $[55,74]$ but are broadly similar to those for other local ablative techniques and are based on size, number and site of HCC in patients who are deemed unsuitable for surgical resection or transplant. The ideal lesions are those of $\leq 3 \mathrm{~cm}$ in diameter, single or one to three nodules each $\leq 3 \mathrm{~cm}$ in diameter, irrespective of their location. Lesions adjacent to major vessels, biliary ducts, bowel, or diaphragm can be treated with caution even with MR-guided technique, but they are more safely approached with fine needle technique [55]. MRguided technique allows confident ablation of anatomically more problematic lesions with the use of real-time thermometry and multiplanar MR targeting [74]. Severe liver disease (Child C) and coagulopathy are relative contraindication to be evaluated in each individual patient, and extrahepatic disease is generally considered an absolute contraindication. LA has also been proven safe and effective for the treatment of cirrhotic patients awaiting liver transplant surgery [75]. Large lesions $\geq 5 \mathrm{~cm}$ can be considered for laser ablation, particularly if using a high-power system, though they can require more than one treatment or/and pullback technique with fine needle method.

2.5. Outcome. LA has been performed mainly via the percutaneous route. The various laser fiber systems with their differing energy delivery levels make it difficult to compare their effectiveness and complication rates. In addition, the ranges of imaging modalities used at follow-up, combined with a variety of definitions of treatment success, make comparison of data difficult. Primary effectiveness relates to complete lesion ablation as assessed by either CT or MR at a defined point after procedure and after a defined number of treatments. Data regarding long-term survival rates for LA in part reflect the novelty of the treatment and the rapid advances in technology, particularly in relation to the laser fibers. LA has been proven safe and feasible for the treatment of HCCs in multiple cohort studies [45, 55, 63, 64, 67, 74, 7679]. The results are summarized in Table 1 . According to the multicenter study involving 432 cirrhotic patients (single tumor $\leq 4 \mathrm{~cm}$ or three nodules $\leq 3 \mathrm{~cm}$ each) with 548 lesions, the ideal candidates for LA are younger ( $<73$ years) patients with normal serum albumin levels and tumor size $\leq 2 \mathrm{~cm}$ who are highly likely to achieve complete tumor ablation [79]. In this study, patients with Child-Turcotte-Pugh class A with tumor size $\leq 3 \mathrm{~cm}$ and a well-differentiated histologic pattern who achieved an initial complete ablation had a median survival time of 65 months (95\% CL, 38 to 92 months), and those with a main tumor size $\leq 2 \mathrm{~cm}$ and sustained necrosis to initial complete response had a median survival time of 63 months ( $95 \%$ CL, 48 to 78 months), which further increased to 68 months (95\% CL, 22 to 114 months) in those with a well-differentiated histology. The median time to recurrence was 24 months (95\% CL, 20 to 28 months), and the median disease-free survival time was 26 months (95\% CL, 22 to 30 months) [79]. Results reported by those groups using water-cooled higher-power MRguided laser ablation have been promising. Eichler et al. [74] reported mean survival rates of 4.4 years ( $95 \%$ CL, 3.6-5.2) in a series of 39 patients with 61 HCCs with complete ablation rate of $98 \%$.

Large lesions can be successfully treated by combining LA with transarterial chemoembolization (TACE). This modality is a safe and effective palliative treatment for large HCC. In the treatment of 30 large lesions $(3.5-9.6 \mathrm{~cm})$ using LA followed by TACE, it was possible to achieve $90 \%$ ablation rate with survival rates of $92 \%, 68 \%$, and $40 \%$ at 1,2 , and 3 years without significant complications [80]. Ferrari et al. [81] supported this suggestion, demonstrating improved ablation rates and survival in patients with $\mathrm{HCC}>5 \mathrm{~cm}$ given combination treatment over LA alone.

2.6. Complications. Reported complication rates for laser ablation compare favorably to those of surgery. Arienti et al. [82] reported complication rates for 520 patients with 647 HCCs treated with 1064 laser sessions considering 90 factors for each record, including tumor characteristics. They report $0.8 \%$ deaths and $1.5 \%$ major complication rate. An earlier report by Vogl et al. [45] included 899 patients, of whom 42 had HCC, with 2520 lesions treated with 2132 laser sessions under CT/MR guidance, with $0.1 \%$ mortality and $1.8 \%$ major complication rate. Both groups reported common side effects of asymptomatic pleural effusion (7.3\% and 6.9\%), postprocedural fever $(33.3 \%$ and $12.3 \%)$, and severe pain (7.5\% and $11.5 \%)$. Neither of the above groups reported tumor seeding. As a rule, tumor seeding has rarely been reported after laser ablation.

2.7. Comparison with Other Hyperthermic Ablative Techniques. In their randomized controlled prospective (RCT) study, Ferrari et al. [83] treated 81 cirrhotic patients with 95 biopsy proven $\leq 4 \mathrm{~cm}$ HCCs comparing LA with RF ablation. Two matched groups were randomized to US-guided RF or LA under general anesthesia. The authors adopted multiple fiber technique using $5 \mathrm{~W}$ per fiber delivering a maximum of $1800 \mathrm{~J}$ per fiber per single illumination [55]. Assessment of response was evaluated by dynamic CT scan. They reported no significant difference overall in survival rates between the two methods, with cumulative rates of $91.8 \%, 59.0 \%$, and $28.4 \%$ at 1,3 , and 5 years, respectively. However, they demonstrated a statistically significant higher survival rate for RF over LA for Child A patients $(P=0.9966)$ and nodules $\leq 2.5 \mathrm{~cm}(P=0.01181)$. They reported no significant complications. This work added to the same groups' previous published improved survival rates in patients treated with LA, compared to those treated with either TACE or percutaneous ethanol injection (PEI) [84]. To date, Di Costanzo et al. (unpublished data) treated in an ongoing RCT (estimated sample, 140 patients) 95 patients with 109 biopsy proven HCCs (single tumor $\leq 5 \mathrm{~cm}$ or three nodules $\leq 3 \mathrm{~cm}$ each) with RF and LA (45 and 52, resp.). The two groups were comparable for median age (71 years), male/female (33/12-RF, 34/16-LA) Child-Turcotte-Pugh A/B (40/5-RF, $46 / 4-\mathrm{LA})$, and median diameter of HCC nodules ( $2.5 \mathrm{~cm}-\mathrm{RF}$, $3.0 \mathrm{~cm}$-LA). With a median follow-up of 9 months (range, 
TABLE 1: Studies reporting the outcome of Laser Ablation for small hepatocellular carcinoma.

\begin{tabular}{|c|c|c|c|c|c|c|c|c|}
\hline \multirow[t]{2}{*}{ Authors } & \multirow[t]{2}{*}{$\begin{array}{c}\text { Number of } \\
\text { tumors/patients }\end{array}$} & \multirow{2}{*}{$\begin{array}{l}\text { Size of tumors } \\
(\mathrm{cm}) \\
\text { mean }(\mathrm{SD})\end{array}$} & \multirow{2}{*}{$\begin{array}{l}\text { Local } \\
\text { recurrence } \\
\text { rate }(\%)\end{array}$} & \multirow{2}{*}{$\begin{array}{l}\text { Complete } \\
\text { ablation* } \\
(\%)\end{array}$} & \multicolumn{2}{|c|}{ Overall survival (\%) } & \multirow{2}{*}{$\begin{array}{c}\text { Major com- } \\
\text { plications } \\
\text { rate }^{* *}(\%)\end{array}$} & \multirow[t]{2}{*}{$\begin{array}{l}\text { Mortality } \\
\text { rate }(\%)\end{array}$} \\
\hline & & & & & 3-year & 5-year & & \\
\hline Giorgio et al. [76] & $85 / 77$ & $3.2(1.0-6.6)$ & 18 & $82.5^{+}$ & & & $3.7^{+}$ & $1.2^{+}$ \\
\hline \multirow{2}{*}{ Pacella et al. [80] } & $30 / 30$ & $\begin{array}{l}5.2 \pm 0.0 \\
(3.5-9.0)\end{array}$ & 7 & $90.0^{+} \mathrm{TACE}$ & $60.0^{\S}$ & & 0 & 0 \\
\hline & $15 / 30$ & $\begin{array}{l}1.9 \pm 3.5 \\
(0.8-3.0)\end{array}$ & 0 & 100.0 & & & 0 & 0 \\
\hline Pacella et al. [67] & $92 / 74$ & $\begin{array}{l}2.4 \pm 0.7 \\
(0.8-4.0)\end{array}$ & 6 & 97.0 & $73.0^{\S}$ & $31.0^{\S}$ & 0 & 0 \\
\hline Eichler et al. [74] & $39 / 61$ & $>2.0$ & 0 & 97.5 & $\begin{array}{c}\text { Mean } 4.4 \\
\text { years }\end{array}$ & & 0 & 0 \\
\hline Dick et al. [64] & $19 / 19$ & & & $50.7^{\#}$ & $\begin{array}{l}\text { Mean } 14.6 \\
\text { months }{ }^{\#}\end{array}$ & & & \\
\hline Pacella et al. [77] & $169 / 148$ & $2.6 \pm 0.8$ & 15 & 82.0 & $58.0^{\S}$ & $30.0^{\S}$ & 0.5 & 0.6 \\
\hline Pacella et al. [79] & $\begin{array}{c}548 / 432 \\
\text { (multicenric study) }\end{array}$ & $2.4 \pm 0.8$ & 20 & 79.6 & & $41.0^{\S}$ & 1.6 & 0.2 \\
\hline
\end{tabular}

${ }^{+}$Calculated in mix histologic tumor types (seventy-seven patients had hepatocellular carcinoma (HCC)). Twenty-seven had metastases from colocarcinoma $(n=25)$ or lung $(n=2)$.

* Calculated per tumor.

**Calculated per patient.

$\S$ Calculated in patients with Child-Turcotte-Pugh class A.

\#Calculated in mix histologic tumor types (nineteen patients had 19 HCCs, eleven patients had metastases from a variety of primary tumors, and five patients had metastatic carcinoid).

1-25 months), complete tumor ablation (CTA) was observed in $95.5 \%$ and $96.0 \%$ of cases in RF and LA, respectively. Overall, HCC recurrence occurred in 24 (15 RF and 9 LA) patients. Local recurrences were 9 in RF group and 3 in LA group. Median time tumor recurrence (TTR) was 15 (95\% CL, 10-20) and 19 (95\% CL, 17-23) months in RF and LA groups, respectively, $(P=0.051)$. One-year progression-free survival rate was $55 \%$ in RF group and $74 \%$ in LA group. One-year survival probability was $92 \%$ and $95 \%$ in RF and LA groups, respectively. Neither major complications nor significant treatment-related morbidity was registered in either groups. Di Costanzo et al. concluded that LA was as effective as RF in inducing the complete response of HCC nodules. A longer TTR and a lower recurrence rate were observed in LA group. These interesting data have to be evaluated and confirmed at the end of the follow-up anticipated in June 2013.

\section{Conclusion}

LA of HCC has proven itself to be a safe and effective local therapy for patients with HCC nodules for whom surgical resection is not possible. Nevertheless, further data from randomized trials are required to establish long-term survival rates for higher-power water-cooled systems before this kind of treatment can be fully validated as a standard treatment. It appears that RF, LA, or MW should replace PEI and cryotherapy, and, to date, there is little difference in outcome between RF and LA using the latest technological developments $[21,85]$.
Thus far, local ablation of hepatic disease has been used for unresectable tumors, but these hyperthermic therapies might be considered as a first-line therapeutic option in the subgroup of patients with HCC nodules $\leq 2 \mathrm{~cm}$ in diameter $[86,87]$ and, in our opinion, particularly in cases with welldifferentiated histologic pattern [79]. In the future, with the refinements of the technology and increased experience with these techniques, it will be possible to safely and completely destroy HCC $\geq 5 \mathrm{~cm}$ as well, even in patients suitable for surgery. The advantage of local tumor destruction include (a) selective damage with a smaller immunosuppression and a smaller release of growth factors [21,88], (b) minimal treatment morbidity and mortality, and (c) the possibility of starting chemotherapy before or at the time of local therapy $[89,90]$. The main problems with in situ ablation are the lack of good imaging techniques to determine the actual extent of disease at intra- and extrahepatic sites and the lack of realtime monitoring of treatment precision and irreversible tissue effect. The percutaneous approach needs to be developed and has not yet been proven to give complete tumor ablation rates that permit its use outside controlled clinical studies. It might be valuable in a few truly unresectable or inoperable patients or in selected patients. In the vast majority of cases, it should still be used and evaluated only in prospective randomized studies.

\section{Conflict of Interests}

The authors declare that they are not shareholders and do not have any financial interests in the companies mentioned 
in this paper that compromised the design of research, the safety and wellbeing of patients, the collection and interpretation of research data, and as well as the dissemination of research results.

\section{References}

[1] D. M. Parkin, F. Bray, J. Ferlay, and P. Pisani, "Global cancer statistics, 2002," Ca: A Cancer Journal for Clinicians, vol. 55, no. 2, pp. 74-108, 2005.

[2] H. B. El-Serag and A. C. Mason, "Rising incidence of hepatocellular carcinoma in the United States," The New England Journal of Medicine, vol. 340, no. 10, pp. 745-750, 1999.

[3] A. H. Olsen, D. M. Parkin, and P. Sasieni, "Cancer mortality in the United Kingdom: projections to the year 2025," British Journal of Cancer, vol. 99, no. 9, pp. 1549-1554, 2008.

[4] G. L. Davis, M. J. Alter, H. El-Serag, T. Poynard, and L. W. Jennings, "Aging of hepatitis $\mathrm{C}$ virus (HCV)-infected persons in the United States: a multiple cohort model of HCV prevalence and disease progression," Gastroenterology, vol. 138, no. 2, pp. 513-521, 2010.

[5] R. P. Beasley, L. Y. Hwang, C. C. Lin, and C. S. Chien, "Hepatocellular carcinoma and hepatitis B virus. A prospective study of 22707 men in Taiwan," The Lancet, vol. 2, no. 8256, pp. 1129-1132, 1981.

[6] M. Sherman, "Surveillance for hepatocellular carcinoma and early diagnosis," Clinics in Liver Disease, vol. 11, no. 4, pp. 817$837,2007$.

[7] C. A. Sun, D. M. Wu, C. C. Lin et al., "Incidence and cofactors of hepatitis $\mathrm{C}$ virus-related hepatocellular carcinoma: a prospective study of 12,008 men in Taiwan," American Journal of Epidemiology, vol. 157, no. 8, pp. 674-682, 2003.

[8] F. Degos, C. Christidis, N. Ganne-Carrie et al., "Hepatitis C virus related cirrhosis: time to occurrence of hepatocellular carcinoma and death," Gut, vol. 47, no. 1, pp. 131-136, 2000.

[9] J. Bruix, M. Sherman, J. M. Llovet et al., "Clinical management of hepatocellular carcinoma. Conclusions of the Barcelona2000 EASL conference," Journal of Hepatology, vol. 35, no. 3, pp. 421-430, 2001.

[10] L. Bolondi, S. Sofia, S. Siringo et al., "Surveillance programme of cirrhotic patients for early diagnosis and treatment of hepatocellular carcinoma: a cost effectiveness analysis," Gut, vol. 48, no. 2, pp. 251-259, 2001.

[11] A. Sangiovanni, E. Del Ninno, P. Fasani et al., "Increased survival of cirrhotic patients with a hepatocellular carcinoma detected during surveillance," Gastroenterology, vol. 126, no. 4, pp. 1005-1014, 2004.

[12] J. Bruix and M. Sherman, "Management of hepatocellular carcinoma," Hepatology, vol. 42, no. 5, pp. 1208-1236, 2005.

[13] B. H. H. Lang, R. T. P. Poon, S. T. Fan, and J. Wong, "Perioperative and long-term outcome of major hepatic resection for small solitary hepatocellular carcinoma in patients with cirrhosis," Archives of Surgery, vol. 138, no. 11, pp. 1207-1213, 2003.

[14] X. D. Zhou, Z. Y. Tang, B. H. Yang et al., "Experience of 1000 patients who underwent hepatectomy for small hepatocellular carcinoma," Cancer, vol. 91, no. 8, pp. 1479-1486, 2001.

[15] W. H. Zhao, Z. M. Ma, X. R. Zhou, Y. Z. Feng, and B. S. Fang, "Prediction of recurrence and prognosis in patients with hepatocellular carcinoma after resection by use of CLIP score," World Journal of Gastroenterology, vol. 8, no. 2, pp. 237-242, 2002.
[16] J. M. Llovet, J. Fuster, and J. Bruix, "Intention-to-treat analysis of surgical treatment for early hepatocellular carcinoma: resection versus transplantation," Hepatology, vol. 30, no. 6, pp. 1434-1440, 1999.

[17] V. Mazzaferro, E. Regalia, R. Doci et al., "Liver transplantation for the treatment of small hepatocellular carcinomas in patients with cirrhosis," The New England Journal of Medicine, vol. 334, no. 11, pp. 693-699, 1996.

[18] V. Mazzaferro, J. M. Llovet, R. Miceli et al., "Predicting survival after liver transplantation in patients with hepatocellular carcinoma beyond the Milan criteria: a retrospective, exploratory analysis," The Lancet Oncology, vol. 10, no. 1, pp. 35-43, 2009.

[19] J. M. Llovet, X. Mas, J. J. Aponte et al., "Cost effectiveness of adjuvant therapy for hepatocellular carcinoma during the waiting list for liver transplantation," Gut, vol. 50, no. 1, pp. 123-128, 2002.

[20] J. M. Llovet and J. Bruix, "Novel advancements in the management of hepatocellular carcinoma in 2008," Journal of Hepatology, vol. 48, no. 1, pp. S20-S37, 2008.

[21] K. G. Tranberg, "Percutaneous ablation of liver tumours," Best Practice and Research: Clinical Gastroenterology, vol. 18, no. 1, pp. 125-145, 2004.

[22] D. B. Brown, J. F. H. Geschwind, M. C. Soulen, S. F. Millward, and D. Sacks, "Society of Interventional radiology position statement on chemoembolization of hepatic malignancies," Journal of Vascular and Interventional Radiology, vol. 20, no. 7, pp. S317-S323, 2009.

[23] R. Lencioni and L. Crocetti, "Image-guided thermal ablation of hepatocellular carcinoma," Critical Reviews in Oncology/Hematology, vol. 66, no. 3, pp. 200-207, 2008.

[24] S. N. Goldberg, C. J. Grassi, J. F. Cardella et al., "Image-guided tumor ablation: standardization of terminology and reporting criteria," Radiology, vol. 235, no. 3, pp. 728-739, 2005.

[25] M. Ahmed, C. L. Brace, F. T. Lee Jr., and S. N. Goldberg, "Principles of and advances in percutaneous ablation," Radiology, vol. 258, no. 2, pp. 351-369, 2011.

[26] S. G. Bown, "Phototherapy of tumors," World Journal of Surgery, vol. 7, no. 6, pp. 700-709, 1983.

[27] A. Masters and S. G. Bown, "Interstitial laser hyperthermia in tumour therapy," Annales Chirurgiae et Gynaecologiae, vol. 79, no. 4, pp. 244-251, 1990.

[28] A. H. Dachman, J. A. McGehee, T. E. Beam, J. A. Burris, and D. A. Powell, "US-guided percutaneous laser ablation of liver tissue in a chronic pig model," Radiology, vol. 176, no. 1, pp. 129-133, 1990.

[29] S. Thomsen, "Pathologic analysis of photothermal and photomechanical effects of laser-tissue interactions," Photochemistry and Photobiology, vol. 53, no. 6, pp. 825-835, 1991.

[30] S. L. Jacques, "Laser-tissue interactions: photochemical, photothermal, and photomechanical," Surgical Clinics of North America, vol. 72, no. 3, pp. 531-558, 1992.

[31] C. P. Nolsoe, S. Torp-Pedersen, F. Burcharth et al., "Interstitial hyperthermia of colorectal liver metastases with a US-guided Nd-YAG laser with a diffuser tip: a pilot clinical study," Radiology, vol. 187, no. 2, pp. 333-337, 1993.

[32] Z. Amin, S. A. Harries, W. R. Lees, and S. G. Bown, "Interstitial tumour photocoagulation," Endoscopic Surgery and Allied Technologies, vol. 1, no. 4, pp. 224-229, 1993.

[33] C. T. Germer, A. Roggan, J. P. Ritz et al., "Optical properties of native and coagulated human liver tissue and liver metastases in the near infrared range," Lasers in Surgery and Medicine, vol. 23, no. 4, pp. 194-203, 1998. 
[34] J. Heisterkamp, R. van Hillegersberg, and J. N. M. IJzermans, "Interstitial laser coagulation for hepatic tumours," British Journal of Surgery, vol. 86, no. 3, pp. 293-304, 1999.

[35] D. R. Wyman, W. M. Whelan, and B. C. Wilson, "Interstitial laser photocoagulation: Nd:YAG $1064 \mathrm{~nm}$ optical fiber source compared to point heat source," Lasers in Surgery and Medicine, vol. 12, no. 6, pp. 659-664, 1992.

[36] K. Ahrar, A. Gowda, S. Javadi et al., "Preclinical assessment of a 980-nm diode laser ablation system in a large animal tumor model," Journal of Vascular and Interventional Radiology, vol. 21, no. 4, pp. 555-561, 2010.

[37] D. N. Wheatley, C. Kerr, and D. W. Gregory, "Heat-induced damage to HeLa-S3 cells: correlation of viability, permeability, osmosensitivity, phase-contrast light-, scanning electron- and transmission electron-microscopical findings," International Journal of Hyperthermia, vol. 5, no. 2, pp. 145-162, 1989.

[38] C. Christophi, A. Winkworth, V. Muralihdaran, and P. Evans, "The treatment of malignancy by hyperthermia," Surgical Oncology, vol. 7, no. 1-2, pp. 83-90, 1998.

[39] P. H. Möller, K. Ivarsson, U. Stenram, M. Radnell, and K. G. Tranberg, "Interstitial laser thermotherapy of adenocarcinoma transplanted into rat liver," European Journal of Surgery, vol. 163, no. 11, pp. 861-870, 1997.

[40] J. P. Ritz, A. Roggan, C. T. Germer, C. Isbert, G. Mller, and H. J. Buhr, "Continuous changes in the optical properties of liver tissue during laser-induced interstitial thermotherapy," Lasers in Surgery and Medicine, vol. 28, no. 4, pp. 307-312, 2001.

[41] A. C. Steger, W. R. Lees, P. Shorvon, K. Walmsley, and S. G. Bown, "Multiple-fibre low-power interstitial laser hyperthermia: studies in the normal liver," British Journal of Surgery, vol. 79, no. 2, pp. 139-145, 1992.

[42] K. Ivarsson, J. Olsrud, C. Sturesson, P. H. Möller, B. R. Persson, and K. G. Tranberg, "Feedback interstitial diode laser $(805 \mathrm{~nm})$ thermotherapy system: ex vivo evaluation and mathematical modeling with one and four-fibers," Lasers in Surgery and Medicine, vol. 22, no. 2, pp. 86-96, 1998.

[43] T. J. Vogl, R. Straub, K. Eichler, O. Söllner, and M. G. Mack, "Colorectal carcinoma metastases in liver: laser-induced interstitial thermotherapy-local tumor control rate and survival data," Radiology, vol. 230, no. 2, pp. 450-458, 2004.

[44] L. M. Veenendaal, A. de Jager, G. Stapper, I. H. M. Borel Rinkes, and R. van Hillegersberg, "Multiple fiber laser-induced thermotherapy for ablation of large intrahepatic tumors," Photomedicine and Laser Surgery, vol. 24, no. 1, pp. 3-9, 2006.

[45] T. J. Vogl, R. Straub, K. Eichler, D. Woitaschek, and M. G. Mack, "Malignant liver tumors treated with MR imagingguided laser-induced thermotherapy: experience with complications in 899 patients (2,520 lesions)," Radiology, vol. 225, no. 2, pp. 367-377, 2002.

[46] W. M. Whelan, D. R. Wyman, and B. C. Wilson, "Investigations of large vessel cooling during interstitial laser heating," Medical Physics, vol. 22, no. 1, pp. 105-115, 1995.

[47] J. Heisterkamp, R. van Hillegersberg, P. G. H. Mulder, E. L. Sinofsky, and J. N. M. Ijzermans, "Importance of eliminating portal flow to produce large intrahepatic lesions with interstitial laser coagulation," British Journal of Surgery, vol. 84, no. 9, pp. 1245-1248, 1997.

[48] P. H. Möller, P. H. Hannesson, K. Ivarsson, J. Olsrud, U. Stenram, and K. G. Tranberg, "Interstitial laser thermotherapy in pig liver: effect of inflow occlusion on extent of necrosis and ultrasound image," Hepato-Gastroenterology, vol. 44, no. 17, pp. 1302-1311, 1997.
[49] C. T. Germer, C. Isbert, D. Albrecht et al., "Laser-induced thermotherapy combined with hepatic arterial embolization in the treatment of liver tumors in a rat tumor model," Annals of Surgery, vol. 230, no. 1, pp. 55-62, 1999.

[50] F. K. Wacker, K. Reither, J. P. Ritz, A. Roggan, C. T. Germer, and K. J. Wolf, "MR-guided interstitial laser-induced thermotherapy of hepatic metastasis combined with arterial blood flow reduction: technique and first clinical results in an open $\mathrm{MR}$ system," Journal of Magnetic Resonance Imaging, vol. 13, no. 1, pp. 31-36, 2001.

[51] V. Muralidharan, C. Malcontenti-Wilson, and C. Christophi, "Effect of blood flow occlusion on laser hyperthermia for liver metastases," Journal of Surgical Research, vol. 103, no. 2, pp. 165-174, 2002.

[52] P. H. Möller, L. Lindberg, P. H. Henriksson, B. R. R. Persson, and K. G. Tranberg, "Temperature control and light penetration in a feedback interstitial laser thermotherapy system," International Journal of Hyperthermia, vol. 12, no. 1, pp. 4963, 1996.

[53] J. Kettenbach, S. G. Silverman, N. Hata et al., "Monitoring and visualization techniques for MR-guided laser ablations in an open MR system," Journal of Magnetic Resonance Imaging, vol. 8, no. 4, pp. 933-943, 1998.

[54] J. Olsrud, R. Wirestam, B. R. R. Persson, and K. G. Tranberg, "Simplified treatment planning for interstitial laser thermotherapy by disregarding light transport: a numerical study," Lasers in Surgery and Medicine, vol. 25, no. 4, pp. 304-314, 1999.

[55] C. M. Pacella, G. Bizzarri, G. Francica et al., "Percutaneous laser ablation in the treatment of hepatocellular carcinoma with small tumors: analysis of factors affecting the achievement of tumor necrosis," Journal of Vascular and Interventional Radiology, vol. 16, no. 11, pp. 1447-1457, 2005.

[56] G. T. Huang, T. H. Wang, J. C. Sheu et al., "Low-power laserthermia for the treatment of small hepatocellular carcinoma," European Journal of Cancer, vol. 27, no. 12, pp. 16221627, 1991.

[57] V. Muralidharan, C. Malcontenti-Wilson, and C. Christophi, "Interstitial laser hyperthermia for colorectal liver metastases: the effect of thermal sensitization and the use of a cylindrical diffuser tip on tumor necrosis," Journal of Clinical Laser Medicine and Surgery, vol. 20, no. 4, pp. 189-196, 2002.

[58] T. J. Vogl, R. Straub, S. Zangos, M. G. Mack, and K. Eichler, "MR-guided laser-induced thermotherapy (LITT) of liver tumours: experimental and clinical data," International Journal of Hyperthermia, vol. 20, no. 7, pp. 713-724, 2004.

[59] K. G. Tranberg, P. H. Möller, P. Hannesson, and U. Stenram, "Interstitial laser treatment of malignant tumours: initial experience," European Journal of Surgical Oncology, vol. 22, no. 1, pp. 47-54, 1996.

[60] D. E. Malone, D. R. Wyman, F. G. DeNardi, F. P. McGrath, C. J. de Gara, and B. C. Wilson, "Hepatic interstitial laser photocoagulation: an investigation of the relationship between acute thermal lesions and their sonographic images," Investigative Radiology, vol. 29, no. 10, pp. 915-921, 1994.

[61] S. A. Harries, Z. Amin, M. E. F. Smith et al., "Interstitial laser photocoagulation as a treatment for breast cancer," British Journal of Surgery, vol. 81, no. 11, pp. 1617-1619, 1994.

[62] R. Joarder, M. de Jode, G. A. Lamb, and W. M. W. Gedroyc, "The value of MnDPDP enhancement during MR guided laser interstitial thermoablation of liver tumors," Journal of Magnetic Resonance Imaging, vol. 13, no. 1, pp. 37-41, 2001. 
[63] T. J. Vogl, K. Eichler, R. Straub et al., "Laser-induced thermotherapy of malignant liver tumors: general principals, equipment(s), procedure(s)—side effects, complications and results," European Journal of Ultrasound, vol. 13, no. 2, pp. 117127,2001

[64] E. A. Dick, R. Joarder, M. de Jode et al., "MR-guided laser thermal ablation of primary and secondary liver tumours," Clinical Radiology, vol. 58, no. 2, pp. 112-120, 2003.

[65] R. Puls, S. Langner, C. Rosenberg et al., "Laser ablation of liver metastases from colorectal cancer with MR thermometry: 5year survival," Journal of Vascular and Interventional Radiology, vol. 20, no. 2, pp. 225-234, 2009.

[66] R. Puls, C. Stroszczynski, C. Rosenberg et al., "Three-dimensional gradient-echo imaging for percutaneous MR-guided laser therapy of liver metastasis," Journal of Magnetic Resonance Imaging, vol. 25, no. 6, pp. 1174-1178, 2007.

[67] C. M. Pacella, G. Bizzarri, F. Magnolfi et al., "Laser thermal ablation in the treatment of small hepatocellular carcinoma: results in 74 patients," Radiology, vol. 221, no. 3, pp. 712-720, 2001.

[68] R. Matsumoto, R. V. Mulkern, S. G. Hushek, and F. A. Jolesz, "Tissue temperature monitoring for thermal interventional therapy: comparison of T1-weighted MR sequences," Journal of Magnetic Resonance Imaging, vol. 4, no. 1, pp. 65-70, 1994.

[69] J. M. MacFall, D. M. Prescott, E. Fullar, and T. V. Samulski, "Temperature dependence of canine brain tissue diffusion coefficient measured in vivo with magnetic resonance echo-planar imaging," International Journal of Hyperthermia, vol. 11, no. 1, pp. 73-86, 1995.

[70] R. D. Peters, R. S. Hinks, and R. M. Henkelman, "Heat-source orientation and geometry dependence in proton-resonance frequency shift magnetic resonance thermometry," Magnetic Resonance in Medicine, vol. 41, no. 5, pp. 909-918, 1999.

[71] E. A. Dick, P. Wragg, R. Joarder et al., "Feasibility of abdomino-pelvic T1-weighted real-time thermal mapping of laser ablation," Journal of Magnetic Resonance Imaging, vol. 17, no. 2, pp. 197-205, 2003.

[72] W. M. W. Gedroyc, "Magnetic resonance guidance of thermal ablation," Topics in Magnetic Resonance Imaging, vol. 16, no. 5, pp. 339-353, 2006.

[73] A. Roggan, I. Mesecke-von Rheinbaben, V. Knappe et al., "Applicator development and irradiation planning in laser-induced thermotherapy (LITT)," Biomedical Engineering, vol. 42, pp. 332-333, 1997.

[74] K. Eichler, M. G. Mack, R. Straub et al., "Oligonodular hepatocellular carcinoma (HCC): MR-guided laser-induced thermotherapy (LITT)," Radiologe, vol. 41, no. 10, pp. 915-922, 2001.

[75] M. Pompili, C. M. Pacella, G. Francica et al., "Percutaneous laser ablation of hepatocellular carcinoma in patients with liver cirrhosis awaiting liver transplantation," European Journal of Radiology, vol. 74, no. 3, pp. e6-e11, 2010.

[76] A. Giorgio, L. Tarantino, G. de Stefano et al., "Interstitial laser photocoagulation under ultrasound guidance of liver tumors: results in 104 treated patients," European Journal of Ultrasound, vol. 11, no. 3, pp. 181-188, 2000.

[77] C. M. Pacella, G. Bizzarri, G. Francica et al., "Analysis of factors predicting survival in patients with hepatocellular carcinoma treated with percutaneous laser ablation," Journal of Hepatology, vol. 44, no. 5, pp. 902-909, 2006.

[78] G. Francica, G. Iodice, M. Delle Cave et al., "Factors predicting complete necrosis rate after ultrasound-guided percutaneous laser thermoablation of small hepatocellular carcinoma tumors in cirrhotic patients: a multivariate analysis," Acta Radiologica, vol. 48, no. 5, pp. 514-519, 2007.

[79] C. M. Pacella, G. Francica, F. M. L. Di Lascio et al., "Longterm outcome of cirrhotic patients with early hepatocellular carcinoma treated with ultrasound-guided percutaneous laser ablation: a retrospective analysis," Journal of Clinical Oncology, vol. 27, no. 16, pp. 2615-2621, 2009.

[80] C. M. Pacella, G. Bizzarri, P. Cecconi et al., "Hepatocellular carcinoma: long-term results of combined treatment with laser thermal ablation and transcatheter arterial chemoembolizationi," Radiology, vol. 219, no. 3, pp. 669-678, 2001.

[81] F. S. Ferrari, A. Stella, D. Gambacorta et al., "Treatment of large hepatocellular carcinoma: comparison between techniques and long term results," Radiologia Medica, vol. 108, no. 4, pp. 356-371, 2004.

[82] V. Arienti, S. Pretolani, C. M. Pacella et al., "Complications of laser ablation for hepatocellular carcinoma: a multicenter study," Radiology, vol. 246, no. 3, pp. 947-955, 2008.

[83] F. S. Ferrari, A. Megliola, A. Scorzelli et al., "Treatment of small HCC through radiofrequency ablation and laser ablation. Comparison of techniques and long-term results," Radiologia Medica, vol. 112, no. 3, pp. 377-393, 2007.

[84] F. Saverio Ferrari, A. Stella, P. Pasquinucci et al., "Treatment of small hepatocellular carcinoma: a comparison of techniques and long-term results," European Journal of Gastroenterology and Hepatology, vol. 18, no. 6, pp. 659-672, 2006.

[85] A. L. Gough-Palmer and W. M. Gedroyc, "Laser ablation of hepatocellular carcinoma-a review," World Journal of Gastroenterology, vol. 14, no. 47, pp. 7170-7174, 2008.

[86] T. Livraghi, F. Meloni, M. Di Stasi et al., "Sustained complete response and complications rates after radiofrequency ablation of very early hepatocellular carcinoma in cirrhosis: is resection still the treatment of choice?" Hepatology, vol. 47, no. 1, pp. 82-89, 2008.

[87] M. Sala, J. M. Llovet, R. Vilana et al., "Initial response to percutaneous ablation predicts survival in patients with hepatocellular carcinoma," Hepatology, vol. 40, no. 6, pp. 13521360, 2004.

[88] M. Nikfarjam, V. Muralidharan, and C. Christophi, "Mechanisms of focal heat destruction of liver tumors," Journal of Surgical Research, vol. 127, no. 2, pp. 208-223, 2005.

[89] G. K. Abou-Alfa, P. Johnson, J. J. Knox et al., "Doxorubicin plus sorafenib vs doxorubicin alone in patients with advanced hepatocellular carcinoma: a randomized trial," Journal of the American Medical Association, vol. 304, no. 19, pp. 2154-2160, 2010.

[90] G. M. Keating and A. Santoro, "Sorafenib: a review of its use in advanced hepatocellular carcinoma," Drugs, vol. 69, no. 2, pp. 223-240, 2009. 


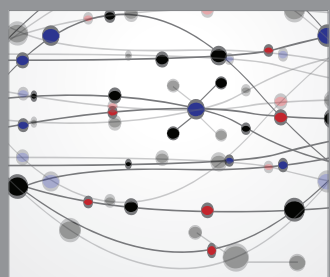

The Scientific World Journal
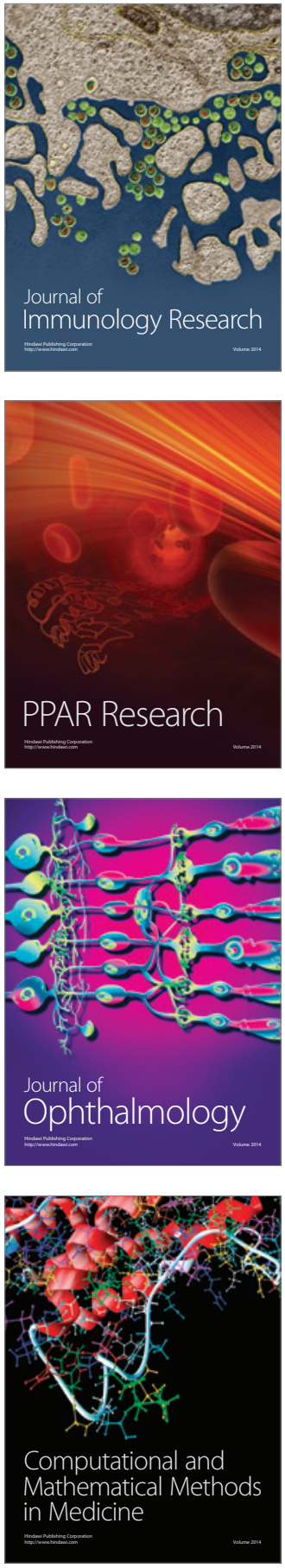

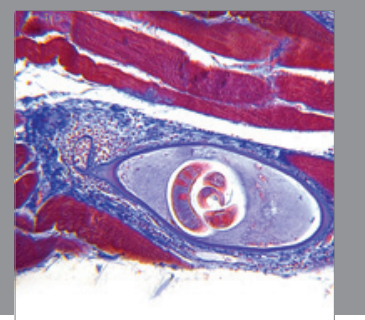

Gastroenterology

Research and Practice
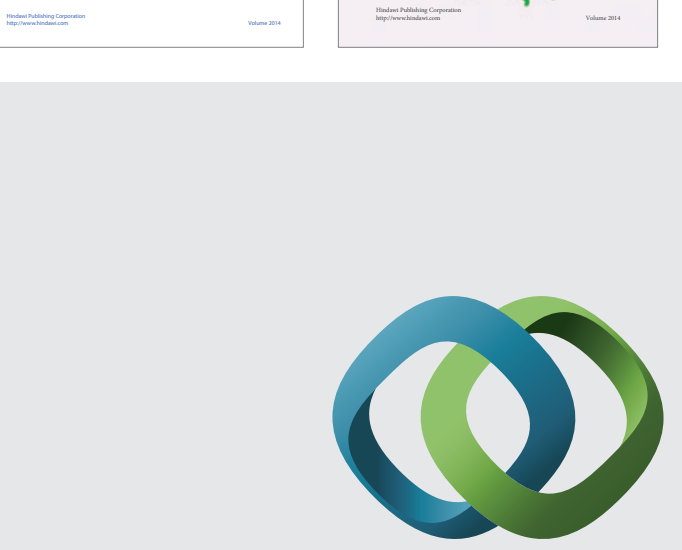

\section{Hindawi}

Submit your manuscripts at

http://www.hindawi.com
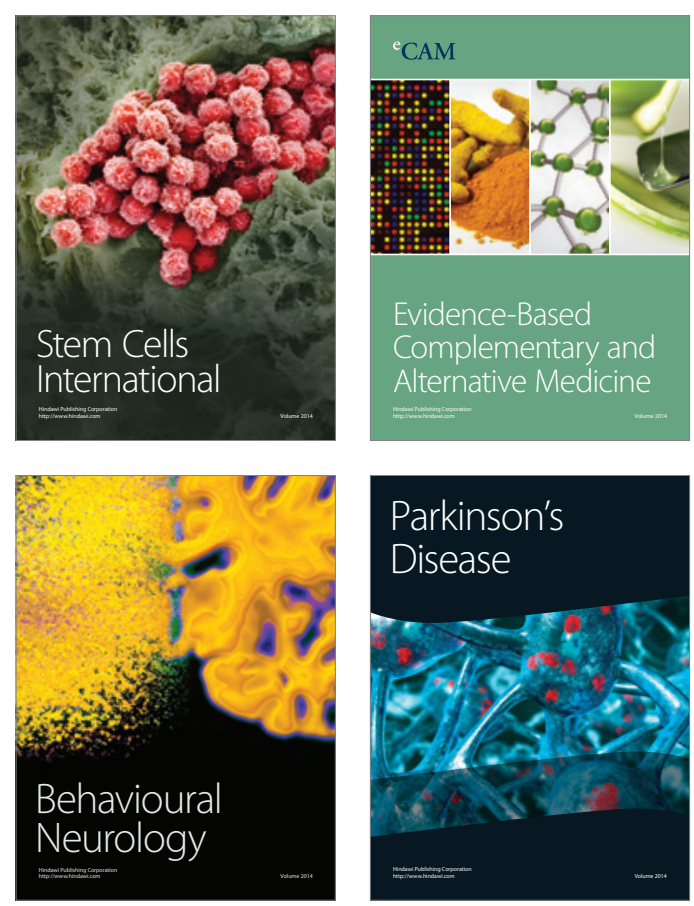

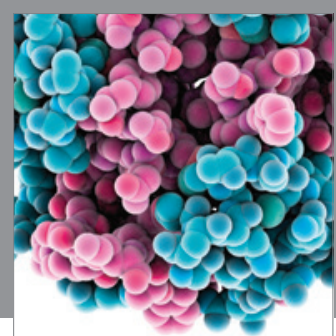

Journal of
Diabetes Research

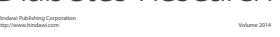

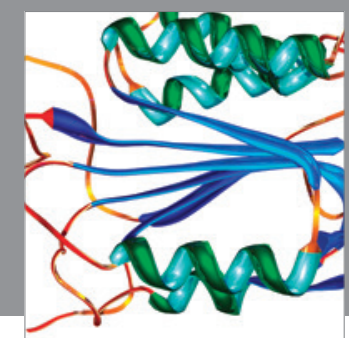

Disease Markers
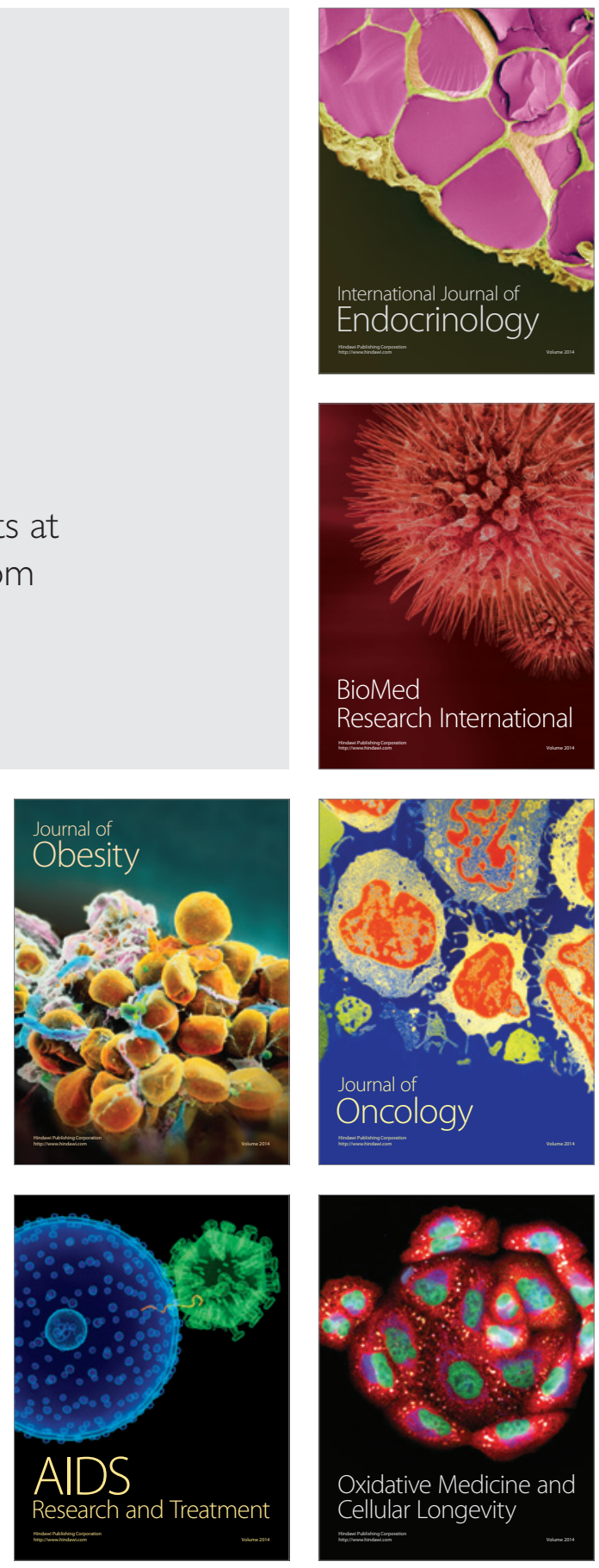